\title{
Yenidoğan izole konjenital kalp bloklarında pacemaker implantasyonu: Tek merkez deneyimi
}

\section{Pacemaker implantation in newborn isolated congenital heart blocks: A single center experience}

\author{
Murat KOÇ
}

Dr.Sami Ulus Eğitim ve Araştırma Hastanesi, Çocuk Kalp ve Damar Cerrahisi Kliniği, Ankara/Türkiye

\section{Öz}

Amaç: Yenidoğan döneminde izole konjenital tam kalp bloğu oldukça nadir görülen bir hastalıktır. Genellikle anne kanında altta yatan immun sistem hastalıklarına bağlı gelişen otoantikorların plasenta yoluyla geçişi ile bebeğin kalp ileti sisteminde fibrozis ile sonuçlanmasının neden olduğu bilinmektedir. Erken dönemde tanı konulmayan ve tedavi edilmeyen hastalarda yüksek oranda ani bebek ölümü ve ciddi morbidite ile kendini gösterir. Bu çalışmadaki amacımız kliniğimizin konu ile ilgili tecrübelerini aktarmaktır.

Gereç ve Yöntemler: Çalışmada 2011-2017 yılları arasında Dr. Sami Ulus Kadın Doğum Çocuk Sağlığı ve Hastalıkları Eğitim ve Araştırma Hastanesi Kalp ve Damar Cerrahisi Kliniğinde izole kalp bloğu nedeniyle cerrahi olarak epikardiyal kalp pili implante edilen 9 hasta (1 erkek, 8 kız) retrospektif olarak incelendi.

Bulgular: Altı hastada (\%67) kalp bloğu tanısı intrauterin hayatta iken yapılan fetal ekokardiyografi incelemesi ile kondu. 3 (\%33) hastamızda ise doğumdan sonra ortaya çıkan bradikardi sonrası çekilen elektrokardiyografiler (EKG) ve transtorasik ekokardiyografi (TTE) incelemeleri ile tanı konuldu. Hastaların 8 (\%89)'inde annede otoimmün bir hastalık bulunmaktaydı. Bunların \%62'si Sistemik Lupus Eritamatozus (SLE) ( $n=5)$, \%38'i Sjögren Sendromu ( $n=3$ ) tanıları ile takip edilmekteydi. Tüm hastalara epikardiyal kalp pili implante edildi. Bir hastada postoperatif 2. ayda sepsis nedeniyle mortalite görüldü. Diğer hastaların takipleri sorunsuz olarak devam etmektedir.

Sonuç: Yenidoğan dönemi tam kalp bloğu yüksek mortalite ve morbidite ile seyreden bir durumdur. Artan tecrübe ile birlikte fetal ekokardiyografi prenatal dönemde birçok konjenital kalp hastalığının tanısının konulmasını sağlamaktadır. Epikardiyal kalp pili implantasyonu mortalite ve morbiditede belirgin derecede azalma sağlayan tek tedavi yöntemidir.

Anahtar kelimeler: yenidoğan, kalp bloğu, kalp pili 


\section{ABSTRACT}

Aim: isolated congenital complete heart block in the neonatal period is a very rare disease. Generally, fibrosis in the conduction system of newborn caused by antibodies of mother with autoimmune disease is responsible for this complete heart block. This situation is related with high risk of sudden infant death and serious morbidities in undiagnosed and untreated newborns. In this study we aim to share our experience about these patients.

Material and Methods: 9 patients (1 male and 8 female) whom implanted epicardial pacemaker due to isolated complete heart block were retrospectively evaluated in Dr. Sami Ulus Maternity and Child Health Research and Training Hospital Cardiovascular Surgery clinic between 2011-2017were evaluated retrospectively in this study.

Results: Disease was diagnosed in 6 (67\%) patients during intrauterine period with fetal echocardiography and in 3 (33\%) patients diagnosis was achieved with electrocardiograpy and transthroacic echocardiography after bradycardia was seen. There were autoimmune disorders in mothers of $8(89 \%)$ infants. $62 \%$ of them were already had Systemic Lupus Erythematosus (SLE) $(n=5)$ and $38 \%$ of them had sjören's syndrome $(n=3)$. Epicardial pacemaker implantation was performed in all of our patients. One postoperative mortality was seen due to sepsis at 2 nd month. Other patients' early and midterm follow-ups have been favorable.

Conclusion: Isolated heart block in newborn has high mortality and morbidity rates. After improvements in technology fetal echocardiography can help us to diagnose a lot of congenital heart disease. Epicardial pacemaker implantation is the only treatment option which can decrease mortality and morbidity rates.

Keywords: newborn, heart block, pacemaker

\section{Giriş}

İole konjenital tam kalp bloğu (KTKB) yaklaşık olarak 15.00022.000 canlı doğumda bir karşılaşılan oldukça nadir bir hastalıktır [1,2]. Çoğunlukla pasif immünite geçişli otoimmün bir hastalı̆̆ın sonucu olarak ortaya çıkmaktadır. Maternal SSA/Ro ve/veya SSB /La spesifik otoantikorlara plasenta yoluyla maruz kalan fetüs ve infantlarda görülmektedir. Bu otoantikorlar gebeliğin 2 . trimesterının ortalarından itibaren fetal dolaşıma girmeye başlar ve yapısal bir defekt olmaksızın iletim sisteminde inflamasyon, kalsifikasyon ve fibrozise neden olarak atriyoventriküler nod seviyesinde iletim bloğuna yol açar. Hastaların annelerinde sıklıkla sjögren sendromu ya da sistemik lupus eritematozus (SLE) bulunmaktadır. Hayatın ilerleyen dönemlerinde ortaya çıkan izole KTKB maternal otoantikorlarla ilişkili değildir $[3,4]$.

Hastalık oldukça nadir görülmesine rağmen doğum öncesi ve sonrasında yüksek oranda mortalite görülmektedir. Bu nedenle düşük seyreden kalp hızı, ventriküler disfonksiyon bulgularının varlığı ve EKG verileri ile erken dönemde kalp pili uygulanması açısından dikkatlice değerlendirilmelidir. Eğer uygun zamanlama ile yeterli kalp hızı sağlanamazsa hastalarda kısa sürede dilate kardiyomiyopati gelişmektedir.
$\mathrm{Bu}$ çalışmada merkezimizde yenidoğan döneminde epikardiyal kalp pili implantasyonu ile tedavi edilen izole KTKB hastalarının erken ve orta dönem özelliklerinin retrospektif olarak değerlendirilmesi amaçlanmıştır.

\section{Gereç ve Yöntemler}

\section{Hastalar:}

Dr. Sami Ulus Kadın Doğum Çocuk Sağlığı ve Hastalıkları Eğitim ve Araştırma Hastanesi Kalpve DamarCerrahisi Kliniğinde 20112017 yılları arasında izole KTKB nedeniyle pediatrik kardiyoloji ve kalp ve damar cerrahisi konseyinden karar alındıktan sonra acil epikardiyal kalp pili implantasyonu yapılan 9 hasta (1 erkek, 8 kız) retrospektif olarak değerlendirildi.

Patent foramen ovale (PFO) ve patent duktus arteriozus (PDA) dışındaki doğumsal kalp defekti bulunan ve doğumsal kalp hastalığı nedeniyle ameliyat olduktan sonra kalp bloğu gelişen hastalar çalışma kapsamı dışında bırakıldı.

Hastaların tüm tıbbi bilgileri hastanemiz tıpta uzmanlık eğitim komisyonu ve başhekimliğinin onayı alındıktan sonra elektronik arşiv kayıtlarından retrospektif olarak incelendi. Hastaların cinsiyeti, gestasyonel yaşı, ameliyat tarihindeki yaşı, ameliyat tarihindeki vücut ağılığı, kalp hızı, elektrokardiyografi 
(EKG) bulguları, ekokardiyografi (EKO) bulguları, kalp pili endikasyonları, ameliyat kayıtları ve pacemaker verileri, kontrol EKG kayıtları ve komplikasyonlar değerlendirildi.

\section{Cerrahi Yöntem:}

Hastalara kalp ve damar cerrahisi ameliyathanesinde ksifoid bölgeden mini sternotomi yapıldı, perikard vertikal olarak açıldı ve sağ ventrikül üzerinde koronerlerden uzak ve uygun eşik değer ölçümü alınan bölgeye Medtronic Capsure ${ }^{\circledR}$ EPI 4968 ya da 4965 epikardiyal elektrot implante edildi. Daha sonra insizyon kaudale doğru uzatıldı ve muskulus rectus abdominis kasının fasiasının altında oluşturulan cebe St. Jude Microny $2525 \mathrm{~T}^{\mathrm{TM}}$ single chamber pacemaker implante edildi (Resim 1). Bir hastada oldukça düşük doğum ağırlığına sahip olması ve yeterli cilt altı dokusunun bulunmaması nedeniyle tam median sternotomi yapıldı, sol plevra açıldı ve batarya diafragma üzerine tespit edildi.

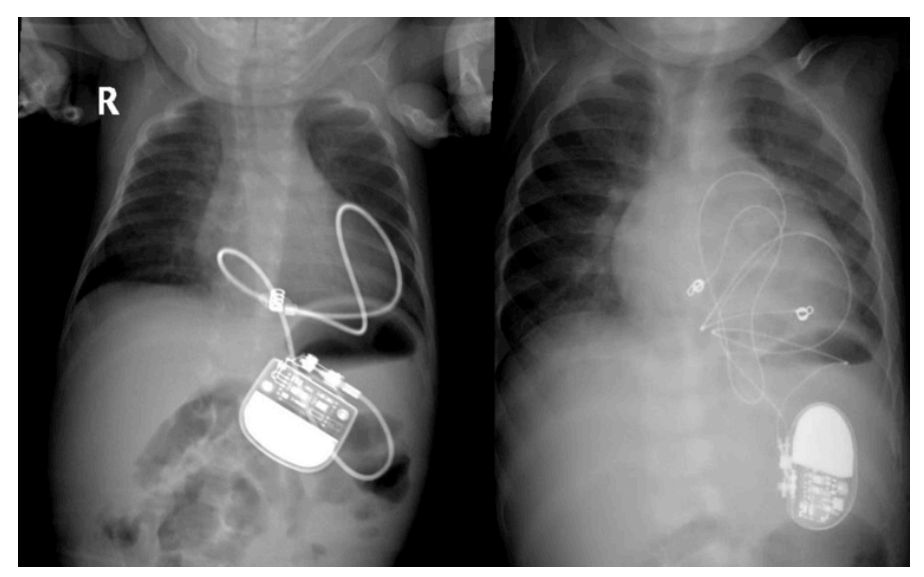

Resim 1: Yenidoğan hastada kalp pili ve elektrotun radyolojik olarak görünümü

\section{İstatistiksel yöntem:}

Çalışma verilerinin istatistiksel analizi için SPSS Windows 16.0 (SPSS Inc. IL, USA) yazılımı kullanıldı. Tanımlayıcı veriler ortalama \pm standart deviasyon, sayı ve sıklık (\%) olarak verildi.

\section{Bulgular}

Altı hastada (\%67) intrauterin dönemdeki takiplerinde fetal ekokardiyografi ile bradikardi ve kalp bloğu tanısı konulmuştu. Prenatal tanı alan hastalarımızın ortalama gestasyonel tanı

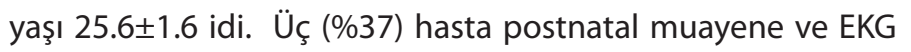
ile tanı almıştı, bu hastaların ikisinin annelerine yapılan klinik ve laboratuvar incelemeler sonrası SLE tanısı konulmuştu. Prenatal dönemde kalp bloğu tanısı almış olan fetüslerin annelerinden üçü SLE, ikisi sjögren sendromu nedeniyle daha önceden takipli iken bir anneye de gebelik sırasında sjögren sendromu tanısı konulmuştu. Bu hastaların annelerinde yapılan serolojik test çalışmalarında ANA $(n=3)$, anti-Ro $(n=2)$ ve anti-La $(n=1)$ sonuçları pozitifti.

Hastaların gestasyonel doğum zamanı en küçük 26 hafta en büyük ise 39 haftaydı (ortalama 33,78 23,93 hafta). İki hastanın (\%22) doğumu normal spontan vajinal yolla 7'sinin (\%78) doğumu ise sezaryen ile gerçekleşmişti. Sezaryen ile doğum endikasyonları; hidrops fetalis $(n=3)$ derin fetal bradikardi (<45 atım/dakika) ile beraber fetal ekokardiyografide her iki ventrikül fonksiyonlarında bozulmaydı $(n=4)$. Doğum ağırlığı en küçük olan hasta 870 gr, en büyüğü ise 3400 gr idi (ortalama $2261 \pm 804 \mathrm{gr}$ ). Hastaların demografik verileri ve kalp hızı verileri Tablo 1'de verilmiştir.

\begin{tabular}{|c|c|c|c|c|c|}
\hline $\begin{array}{l}\text { Hasta } \\
\text { No }\end{array}$ & $\begin{array}{c}\text { Gestasyo- } \\
\text { nel doğum } \\
\text { zamanı (hafta) }\end{array}$ & Cinsiyet & $\begin{array}{l}\text { Ağırlığı } \\
\text { (gram) }\end{array}$ & $\begin{array}{l}\text { Annede } \\
\text { otoim- } \\
\text { mün } \\
\text { hastalık }\end{array}$ & $\begin{array}{l}\text { Kalp Hızı } \\
\text { (atım/ } \\
\text { dakika) }\end{array}$ \\
\hline 1 & 26 & $\mathrm{~K} \mathrm{Iz}$ & 870 & SLE & 39 \\
\hline 2 & 34 & Erkek & 2200 & SLE & 45 \\
\hline 3 & 31 & $\mathrm{~K} \mathrm{IZ}$ & 1500 & $\begin{array}{l}\text { Sjögren } \\
\text { Sendromu }\end{array}$ & 48 \\
\hline 4 & 32 & Kız & 2100 & SLE & 54 \\
\hline 5 & 33 & $\mathrm{~K} \mathrm{Iz}$ & 2000 & SLE & 52 \\
\hline 6 & 35 & $\mathrm{~K} I \mathrm{z}$ & 2280 & SLE & 46 \\
\hline 7 & 39 & $\mathrm{~K} \mathrm{Iz}$ & 3400 & yok & 45 \\
\hline 8 & 38 & $\mathrm{~K} \mathrm{Iz}$ & 3300 & $\begin{array}{l}\text { Sjögren } \\
\text { Sendromu }\end{array}$ & 55 \\
\hline 9 & 36 & $\mathrm{~K} \mathrm{Iz}$ & 2700 & $\begin{array}{l}\text { Sjögren } \\
\text { Sendromu }\end{array}$ & 50 \\
\hline
\end{tabular}

İntrauterin olarak kalp bloğu tespit edilen hastalarda fetal dönemde maternal deksametazon ile tedavi uygulanmış fakat bu hastalarda tedaviye yanıt alınamamıştı. Doğum sonrası tüm hastalara bradikardi ve düşük kalp debisi nedeniyle erken dönemden itibaren dopamin ve adrenalin infüzyonu ile inotropik destek tedavisi uygulandı. Antiinflamatuar tedavi amacıyla intravenöz gamaglobülin (IVIG) $(n=3)$ ve hidrokortizon $(n=4)$ tedavileri verildi. Kalp hızını artırmak için isoproteronol infüzyonu uygulanmasına rağmen hastalarda yeterli kalp hızı ve kalp debisi sağlanamadı.

Tüm hastalara kalp pili implantasyonu kararı pediatrik kardiyoloji ve kalp ve damar cerrahisi konseyi tarafından verilmişti. Kalp pili endikasyonları bradikardi ( $<50$ atım/ dakika), düşük kalp debisi bulgularının varlığı ve kan gazında metabolik asidoz idi.

Hastaların ortalama ameliyat yaşı $2 \pm 1,11$ gündü. Üç hastada doğumdan sonraki ilk 24 saat içerisinde kalıcı kalp pili implante edilmişti. En erken implantasyon uygulanan hasta 
6 saatlik iken en geç uygulanma yaşı 4 gündü. Hastaların tamamında elektrot sağ ventrikül üzerinde eşik değer ölçümü yapıldıktan sonra 1,5 milivolt ( $\mathrm{mV}$ ) altındaki en iyi değer alınan bölgeye yerleştirildi. Ameliyatta en düşük eşik değer 0,7 mV,

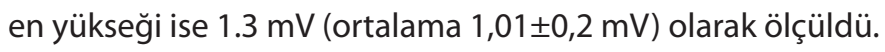

Hastalar ameliyat sonrası ilk 6 saat kalp ve damar cerrahisi yoğun bakım ünitesinde daha sonrasında ise yenidoğan yoğun bakım ünitesinde takip edilmişlerdi. Tüm hastalara verilen inotropik destek tedavileri, kalp pili implantasyonu ile yeterli kalp hızı ve debisinin sağlandığı görülerek sonlandırıldı.

Pil kontrolleri ve TTE ile ventrikül fonksiyonlarının değerlendirilmesi ameliyat sonrası 24. saatte, 1. ayda, 6. ayda ve 12. ayda yapıldı ve bundan sonra senelik olarak devam edildi. Hastaların ortalama takip süresi $39.1 \pm 27.5$ ay idi. Hastaların hiçbirinin takibinde ventriküler dilatasyon ya da fonksiyon bozukluğu görülmedi.

Bir hastada ameliyat sonrası 15. günde bataryanın üzerindeki bölgede cilt traksiyonu gözlenmesi üzerine revizyon gerekli görüldü ve cep tekrar açılarak batarya rectus abdominis kasının posterior fasiası altında peritonun üzerine alındı.

Hasların hiçbirinde epikardiyal elektrotlarda bozukluk ve değişim ihtiyacı olmazken iki hastada 4. yılda ve bir hastada 5. yılda batarya değişimi gerektiği için yalnızca batarya değişimi yapıldı.

Gestasyonel yaşı 26 hafta ve doğum ağırlığı 870 gram olan hastada kalp pili implantasyonundan 2 ay sonra yenidoğan yoğun bakım ünitesinde sepsis nedeniyle mortalite görüldü. Diğer hastaların takiplerine sorunsuz olarak devam edilmektedir.

\section{Tartışma}

İzoleKTKB kendiliğinden ortayaçıkan,fetaldönemde,doğumda ya da yaşamın ilk bir ayında teşhis edilen tam atriyoventriküler bloğu tanımlamaktadır. Kalpte yapısal bir defekt olmaksızın görülen kalp bloğunun etiyolojisinde annede bulunan anti-Ro ve/veya anti-La otoantikorlarının plasenta yoluyla geçişi \%6090 oranında rol oynamaktadır, daha nadiren idiyopatik olarak ortaya çıkmaktadır [4,5]. Bizim hastalarımızın \%66 sı ( $n=6)$ fetal hayatta iken tanı konulmuş ve doğum sonrasında epikardiyal kalp pili implantasyonu için takip altına alınmıştı. Maternal SLE hastaların $\% 57$ 'sinde $(n=5)$, sjögren sendromu ise $\% 33$ 'ünde $(n=3)$ tespit edildi. Hastalarımızın \%11 inde $(n=1)$ ise herhangi bir otoimmün hastalık veya doğumsal kalp defekti tespit edilemedi ve idiyopatik olarak değerlendirildi.

Fetal hayatta hastalığın tanısının konulmasında fetal ekokardiyografi altın standart yöntemdir [6]. Gestasyonel hayatın 20. haftasından önce dahi rahatlıkla tanı konulabilmektedir. Hastaların yaklaşık yarısında fetal ekokardiyografik inceleme ile 24 . gestasyonel haftada tanı konulabildiği bildirilmektedir [7]. Çalışma grubumuzda prenatal tanı alan hastalarımızın ortalama gestasyonel tanı

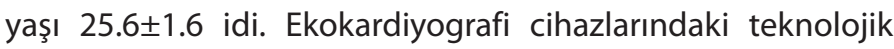
gelişmeler yanında fetal ekokardiyografi yapılan merkez sayısının artması ile risk grubundaki hastalarda daha erken tanısal değerlendirilmeler yapılabilmektedir. Fakat tanı konulan hastalarda prenatal tedavi seçenekleri halen oldukça kısıtlıdır. Farmakolojik tedavi yöntemleri denenmiş fakat başarılı sonuçlar elde edilememiştir [8]. Son yıllarda intrauterin fetal kalp pili uygulamaları ile ilgili çalışmalar yapılmış olsa da uygulamadan sonraki saatler içerisinde fetüsün kaybı ile sonuçlanmıştır [9]. Bu nedenle intrauterin dönemde artmış fetal stres, hidrops fetalis bulguları, kalp hızının 55 atım/dakika altında olması ve ventrikül foksiyonlarında bozukluk tespit edildiğinde doğumun hayatla bağdaşan en erken döneme alınması ve hastaya epikardiyal kalp pili yerleştirilmesi mortalite ve morbidite üzerinde en etkili tedavi seçeneğidir [10]. Kalp hızı 55 atım/dakika altında olan ve pacemaker implantasyonu yapılmayan hastalarda hızla dilate kardiyomiyopati gelişmektedir. Bu hastalarda \%75 oranında mortalite geliştiği bildirilmektedir [10]. Bizim hastalarımızın \%33 ünde $(n=3)$ intrauterin hidrops fetalis bulguları nedeniyle doğum erkene alınmış ve doğum sonrası epikardiyal kalp pili implantasyonu yapılmıştı.

America College of Cardiology (ACC) ve American Heart Asociation (AHA)'nın 2008 yılında yayınlamış oldukları kılavuzda; geniş QRS kaçış ritmi olması, ventriküler disfonksiyon bulunması, ventrikül hızı <55 atım/dakika olması veya doğumsal kalp hastalığı ile beraber ventrikül hızı $<70$ atım/dakika olması durumlarını kalıc kalp pili implantasyonu için klas 1 endikasyon olarak önerilmektedirler [11]. Çalışma grubumuzdaki tüm hastalara pediatrik kardiyoloji kalp damar cerrahisi konseyi tarafından kalp pili implantasyonu endikasyonu kararı verilmesinin ilgili klavuzlarla uyumlu olduğu görülmüştür.

Kalp pilinin epikardiyal ya da transvenöz endokardiyal yöntemlerin hangisiyle uygulanacağı konusu pediatrik hastalar için oldukça tartışmalıdır. Yenidoğan yaş grubunda vasküler erişimdeki zorluklar, yüksek orandaki vasküler oklüzyon riski ve kardiyak yaralanma riski nedeniyle epikardiyal elektrot kullanılarak kalıcı kalp pili implantasyonu daha güvenli olarak kabul edilmektedir. Ayrıca transvenöz endokardiyal yöntemle 
kalp pili implante edilen yenidoğanlarda yetersiz cilt altı dokusu ve iyi gelişmemiş toraks duvarı kasları nedeniyle bu bölgede batarya cebi oluşturulması güçlükler içermekte, genelde bataryanın cilt dokusunda yaptığı gerilmeye bağlı cilt erozyonu ve nekrozu gelişmektedir [12]. Epikardiyal yöntemde ise karın ön duvarı ve rectus abdominis kasının fasyasının altında yeterli ve uygun batarya cebi oluşturulacak alan elde edilebilmektedir. Çok küçük doğum ağırlığına sahip infantlarda ise plevral boşluk pil bataryası için kullanılabilmektedir [13]. Çalışma grubumuzdaki 870 gram ağırlığındaki bir hastaya kalp pili bataryası sol plevral boşlukta diafragma üzerine tespit edilmişti. Diğer hastalarımızın tamamında batarya cebi olarak karın ön duvarı rectus abdominis kasının fasiyasının altı kullanılmıştı. Bir hastamızda batarya cebi bölgesinde ciltte traksiyon gözlenmesi üzerine ameliyat sonrası 15. günde cep bölgesi revize edilerek batarya fasiya ile periton arası boşluğa tespit edilmişti. Sonrasında yara iyileşmesi sorunsuz olarak gerçekleşmiş ve kontrollerinde de bir sorunla karşılaşılmamıştı. Merkezimizde takip ettiğimiz 10 kg'dan daha az vücut ağırlığında olan tüm hastalarımız için ülkemizde markette bulunan en küçük hacimli batarya kullanılması tercih edilmektedir. Bu durumun batarya ömrü açısından bir dezavantaj oluşturacağı düşünülebilir. Ancak merkezimizde izlenen hastalarımızda bataryaya bağlı olarak büyüme ve gelişmesi devam eden cilt-altı ve kas dokularında yara komplikasyonlarının oldukça az görülmesinin bu uygulamanın olumlu bir sonucu olduğu düşünülmektedir.

Hastalarımızın tamamında kalp pilini VVI modunda ve 140170 arası atım/dakika hızında başlatılarak kontrollerinde kalp hızı yaşına ve ventrikül fonksiyonlarına göre değiştirildi. Literatürde devamlı sağ ventrikül üzerinden iletim oluşturulan kalıcı kalp pili hastalarında sol ventrikül fonksiyonların bozulma ve \%7 oranında kalp pili bağımlı kardiyomiyopati bildirilmiştir [14]. Bizim hastalarımız da bu açıdan yakın olarak takip edilmektedir. Ortalama takip süresi $39.1 \pm 27.5$ ay olan hastalarımızın kontrollerinde sol ventrikül fonksiyonları normal olarak izlenmiştir.

İole KTKB hastaları gerek intrauterin dönemde gerekse yenidoğan döneminde \%19 oranında mortalite ile seyreden önemli bir yenidoğan kalp hastalığıdır [15]. Erken dönemde tanı ve kalıcı kalp pili tedavisi mortaliteyi önemli oranda azaltır. Hastalarımızda mortalite oranı \%11 $(n=1)$ olarak görüldü. Mortalite gelişen hastamızın intrauterin hidrops fetalis ve fetal ekokardiyografik incelemesinde ileri derece sol ventrikül fonksiyonunda bozulma görülmesi üzerine 26. gestasyonel haftasında ve 870 gram ağırlığında iken doğumu sezaryen ile gerçekleştirildi. Postoperatif takiplerinde kalp fonksiyonları düzelen hasta ikinci ayında sepsis nedeniyle kaybedildi.

\section{Sonuç}

Yenidoğan dönemi KTKB oldukça nadir görülen bir hastalık olsa da tedavi edilmediğinde yüksek oranda mortalite ve morbidite ile seyreder. Kalp pili implantasyonu yapılmayan hastalarda erken dönemde dilate kardiyomiyopati gelişeceği için hastaların erken tanısı ve en kısa sürede kalp pili implantasyonu ile tedavisi hayat kurtarıcı olduğu için önemlidir. Fetal ekokardiyografi değerlendirmelerinin yaygınlaşması ile günümüzde fetal hayatın erken dönemlerinde tanı konulabilen hastaların çocuk kalp cerrahi bulunan bir merkezde doğması ya da doğumdan sonra hızlıca bu merkezlere transportu mortalite ve morbiditede önemli oranda azalma sağlayacaktır. Tek bir merkezin sonuçlarının değerlendirildiği çalışmamızda oldukça nadir görülen bir hastalık olması nedeniyle vaka sayısı oldukça sınırlıdır. Bu konuda daha geniş vaka serileriyle çok merkezli ve prospektif çalışmalara intiyaç vardır.

\section{Çıkar çatışması / finansal destek beyanı}

Bu yazıdaki hiçbir yazarın herhangi bir çıkar çatışması yoktur. Yazının herhangi bir finansal desteği yoktur

\section{Kaynaklar:}

1. Michaëlsson M, Engle MA. Congenital complete heart block: an international study of the natural history. Cardiovasc Clin 1972; 4: $85-101$

2. Brito-Zerón P, Izmirly PM, Ramos-Casals M, Buyon JP, Khamashta MA. The clinical spectrum of autoimmune congenital heart block. Nat Rev Rheumatol 2015; 11: 301-12

3. Capone C, Buyon JP, Friedman DM, Frishman WH. CardiaC manifestations of neonatal lupus: a review of autoantibodyassociated congenital heart block and its impact in an adult population. Cardiol Rev 2011; 20: 72-76

4. Baruteau AE, Fouchard S, Behaghel $A$ et al. Characteristics and long-term outcome of non-immune isolated atrioventricular block diagnosed in utero or early childhood: a multicentre study. Eur Heart J 2012; 33: 622-29

5. Brito-Zerón P, Izmirly PM, Ramos-Casals M, Buyon JP, Khamashta MA Autoimmune congenital heart block: complex and unusual situations. Lupus 2016; 25: 116-28

6. Donofrio MT, Moon-Grady AJ, Hornerger LK, et al. Diagnosis and Treatment of Fetal Cardiac Disease: A Scientific Statement From the American Heart Association. Circulation 2014; 129: 2183-242 
7. Buyon JP, Hiebert R, Copel J et al. Autoimmune-associated congenital heart block: demographics, mortality, morbidity and recurrence rates obtained from a national neonatal lupus registry. J Am Coll Cardiol 1998; 31: 1658-66

8. Assad RS, Zielinsky P, Kalil R et al. New lead for in utero pacing for fetal congenital heart block. J Thorac Cardiovasc Surg 2003; 126: $300-2$

9. Vest AN, Zhou $L$, Huang $X$ et al. Design and Testing of a Transcutaneous RF Recharging System for a Fetal Micropacemaker. IEEE Trans Biomed Circuits Syst 2017; 11: 336-46

10. Eronen $M$, Sirèn $M K$, Ekblad $H$, Tikanoja $T$, Julkunen $H$, Paavilainen T. Short-and long-term outcome of children with congenital complete heart block diagnosed in utero or as a newborn. Pediatrics 2000; 106: 86-91.

11. Epstein $A E$, Dimarco JP, Ellenbogen $K A$ et al. ACC/AHA/HRS 2008 guidelines for device-based therapy of cardiac rhythm abnormalities: a report of the American College of Cardiology/ American Heart Association Task Force on Practice Guidelines (Writing Committee to Revise the ACC/AHA/NASPE 2002 Guideline Update for Implantation of Cardiac Pacemakers and Antiarrhythmia Devices) developed in collaboration with the American Association for Thoracic Surgery and Society of Thoracic Surgeons. Journal of the American College of Cardiology, 2008; 51: 1-62.
12. Kubus $P$, Materna $O$, Gebauer RA et al. Permanent epicardial pacing in children: long-term results and factors modifying outcome. Europace 2012; 14: 509-14

13. Silvetti MS, Drago F, De Santis A et al. Single-centre experience on endocardial and epicardial pacemaker system function in neonates and infants. Europace 2007; 9: 426-31

14. Moak JP, Hasbani K, Ramwell C et al. Dilated Cardiomyopathy Following Right Ventricular Pacing for AV Block in Young Patients: Resolution After Upgrading to Biventricular Pacing Systems. J. Cardiovasc. Electrophysiol 2006; 17: 1068-71

15. Karpawich PP, Singh $H$, Zelin K. Optimizing paced ventricular function in patients with and without repaired congenital heart disease by contractility-guided lead implant. Pacing Clin. Electrophysiol 2015; 38: 54-62 